\title{
The Effect of Reclaimed Asphalt Pavement (RAP) Aggregates on the Reaction, Mechanical Properties and Microstructure of Alkali-Activated Slag
}

\author{
Juliana O. Costa ${ }^{1,2, *}$, Paulo H. R. Borges ${ }^{1}$ (D) Flávio A. dos Santos ${ }^{1}$, Augusto Cesar S. Bezerra ${ }^{1} \mathbb{D}$, Johan Blom ${ }^{2} \mathbb{D}$ \\ and Wim Van den bergh ${ }^{2}$ \\ 1 Department of Civil Engineering, Federal Center for Technological Education of Minas Gerais (CEFET-MG), \\ Belo Horizonte 30510-000, Brazil; paulo.borges@cefetmg.br (P.H.R.B.); flaviosantos@cefetmg.br (F.A.d.S.); \\ augustobezerra@cefetmg.br (A.C.S.B.) \\ 2 EMIB Research Group, Faculty of Applied Engineering, University of Antwerp, 2020 Antwerp, Belgium; \\ johan.blom@uantwerpen.be (J.B.); wim.vandenbergh@uantwerpen.be (W.V.d.b.) \\ * Correspondence: Juliana.OliveiraCosta@uantwerpen.be
}

check for updates

Citation: Costa, J.O.; Borges, P.H.R.; dos Santos, F.A.; Bezerra, A.C.S.; Blom, J.; Van den bergh, W. The Effect of Reclaimed Asphalt Pavement (RAP) Aggregates on the Reaction, Mechanical Properties and Microstructure of Alkali-Activated Slag. CivilEng 2021, 2, 794-810. https://doi.org/10.3390/ civileng2030043

\section{Academic Editors:}

João Castro-Gomes, Cristina Fael and Miguel Nepomuceno

Received: 27 July 2021

Accepted: 31 August 2021

Published: 4 September 2021

Publisher's Note: MDPI stays neutral with regard to jurisdictional claims in published maps and institutional affiliations.

Copyright: (c) 2021 by the authors. Licensee MDPI, Basel, Switzerland. This article is an open access article distributed under the terms and conditions of the Creative Commons Attribution (CC BY) license (https:/ / creativecommons.org/licenses/by/ $4.0 /)$.
Abstract: Reclaimed asphalt pavement (RAP) is a recyclable aggregate produced during the demolition of old flexible pavements and consists of natural aggregates (NA) coated with aged bitumen. The detrimental effect caused by the bitumen coating on strength and porosity has limited the use of RAP on traditional cementitious systems. This study investigates the potential use of fine RAP to substitute NA in the production of alkali-activated slag mortars (AAM). The effect of different activator dosages was assessed, i.e., either $4 \%$ or $6 \% \mathrm{Na}_{2} \mathrm{O}$ (wt. slag) combined with a modulus of silica equal to $0,0.5$ and 1.0. The characterisation of $100 \%$ RAP-AAM consisted of hydration kinetics (Isothermal Calorimetry), pore size distribution (Mercury Intrusion Porosimetry), mechanical performance (Compressive and Flexural strength), and microstructure analysis (Scanning Electron Microscopy and Confocal Laser Scanning Microscopy). The results show that RAP aggregates do not compromise the reaction of the matrices; however, it causes a significant strength loss (compressive strength of RAP-mortars $54 \%$ lower than reference NA-mortar at 28 days). The higher porosity at the interface transition zone of RAP-AAM is the main responsible for the lower strength performance. Increasing silicate dosages improves alkaline activation, but it has little impact on the adhesion between aggregate and bitumen. Despite the poorer mechanical performance, $100 \%$ RAP-AAM still yields enough strength to promote this recycled material in engineering applications.

Keywords: RAP; alkali-activated materials; recycled aggregates; calorimetry; microstructure

\section{Introduction}

Reclaimed asphalt pavement (RAP) is generated during the removal of existing flexible pavements. It consists of natural aggregates particles partially or entirely covered with aged bitumen. Over 100 million tons of RAP are produced yearly in Europe and the USA [1], but not all of these materials find their way back to the production chain as re-used aggregate in asphalt production. Most recycling efforts focus on using RAP in new hot-mix asphalt or as granular materials for unbound pavement layers [1-3], but for both alternatives, there is a limit to the replacement level and a relatively high amount of RAP is left unused $[4,5]$.

Many researchers [6-11] have successfully studied the incorporation of RAP in base and subbase layers for the pavement section. High RAP replacement levels lead to a loss of mechanical properties, which can be compensated by using stabilisers, i.e., agents that increase the compressive and impact strength and the overall integrity of the layers (reduction of swelling, shrinkage, abrasion, etc.) [5,6]. It is possible to stabilise RAP using stabilisers such as lime, cement, fly ash, blast furnace slag, rice husk ash, sugar cane bagasse ash, among others [7-9,11]. While an extremely high dosage of Ca-rich stabilisers 
is discouraged - as it may cause shrinkage, cracking, and failure of the pavement-the use of a low Ca stabiliser may not impair sufficient strength; therefore, sometimes, it is possible to employ alkali activation to meet the strength requirement for base materials $[10,12]$. The alkali activation in RAP base/subbase layers may help compensate for the strength loss.

Alkali-activated materials (AAM) emerged in the last three decades as sustainable building materials to replace Portland cement for some applications [13]. These binders rely on the alkaline activation of mainly natural or calcined clay materials and industrial residues or wastes, such as pulverised fly ash, ground granulated blast furnace slag (GG$\mathrm{BFS})$, mining residues, among others [13-16]. The most used alkaline activators are sodium silicate, sodium hydroxide, sodium carbonate, potassium hydroxide and potassium silicate [17]. The final activated product may present high strength, chemical resistance (acidic and sulphate environments), and comparable chloride ingress to OPC-based materials [13].

The literature on the alkaline activation of base and subbase pavement layers containing RAP materials is still scarce; some of the main research on RAP and AAM is presented in Table 1. A recent study presented the challenges, opportunities, and research needs [18]. Hoy et al. and Horpibulsuk et al. $[19,20]$ presented results of RAP stabilised with alkaliactivated high calcium $(\mathrm{CaO}>10 \%)$ pulverised fly ash (PFA) for base courses. SEM and XRD analysis indicate that the main activation products were C-A-S-H and N-A-S-H gels and that the coexistence of both hydrates increased the strength, which was proportional to the $\mathrm{Na}_{2} \mathrm{SiO}_{3}$ content. The absence of silicates resulted in low activation of RAP-PFA systems, similar to conventional alkali-activated concretes [19]. The authors also found C-S-H as a hydration product with higher calcium content, such as GGBFS [12].

Table 1. Main studies on RAP and AAM.

\begin{tabular}{|c|c|c|}
\hline Authors & System & Main Findings \\
\hline Hoy et al. $[12,19,21]$ & Stabilised RAP using Fly ash or slag & $\begin{array}{l}\text { Better durability with higher } \mathrm{NaOH} \text { content; excess } \\
\mathrm{Na}_{2} \mathrm{SiO}_{3} \text { can cause strength loss, low leachates. }\end{array}$ \\
\hline Avirneni et al. [5] & Stabilised RAP/NA/fly ash & Minimum strength loss due to wet/dry cycles. \\
\hline Saride et al. [22] & RAP/NA/Fly ash & RAP exposed surface is $15-70 \%$. \\
\hline Mohammadinia et al. [23] & Stabilised RAP_Fly ash/slag & Viable and sustainable material for pavements. \\
\hline Horpibulsuk et al. [20] & Stabilised RAP/Fly ash & Reduced leachability of heavy metals. \\
\hline Jallu et al. [24] & Stabilised RAP/NA using FA & Flexural fatigue behavior improved with geogrid. \\
\hline Hossiney et al. [25] & RAP/slag paver blocks & Lower strength and abrasion resistance compared with NA. \\
\hline Rahman et al. [26] & Roller compacted RAP- fly ash & Adequate strength for pavement material. \\
\hline
\end{tabular}

Miranda et al. [27] examined a full-scale application $20 \%$ alkali-activated FA stabilised (sub)base layer. The authors observed that the alkali-activated samples presented strength and stiffness values similar or superior to control samples (stabilised with 5\% PC). Furthermore, mechanical properties improvements caused by the addition of sodium silicate to the activating solution $(\mathrm{NaOH})$ reduced over time, suggesting that $\mathrm{Na}_{2} \mathrm{SiO}_{3}$ had arguable benefits in the long term (90 days).

These preliminary studies also conclude that, similarly to RAP-OPC systems, the bitumen layer's presence is detrimental to RAP binding to the matrix. In other words, the RAP particles presented better bonding to the matrix for exposed aggregate surfaces, i.e., surfaces free from bitumen. Hence, better performance may be achieved if a milling procedure guarantees a higher exposed aggregate area [22].

The main objective of this study is to evaluate the impact of the replacement of natural aggreges with RAP on the mechanical properties of GGBFS-based AAM (Figure 1). A better understand of how RAP aggregates impact the properties of AAM could enable the use of this materials as pavement layers and offer another possibility for recycling RAP. The literature has not covered three main questions, and we aim to answer herein: (i) the impact of the alkali content and RAP addition on the reaction of AAM; (ii) the effect of the alkali concentration on the mechanical properties (compressive and flexural strength) 
of the mortars containing RAP; (iii) the effect of RAP aggregates on the microstructure and porosity of the mortars. To the authors' knowledge, this paper is the first one to present results on the use of Isothermal Calorimetry, Mercury Intrusion Porosimetry (MIP) and the combination of Confocal Laser Scanning Microscopy (CLSM) with Scanning Electron Microscopy (SEM) in the characterisation of alkali-activated materials containing RAP aggregates.

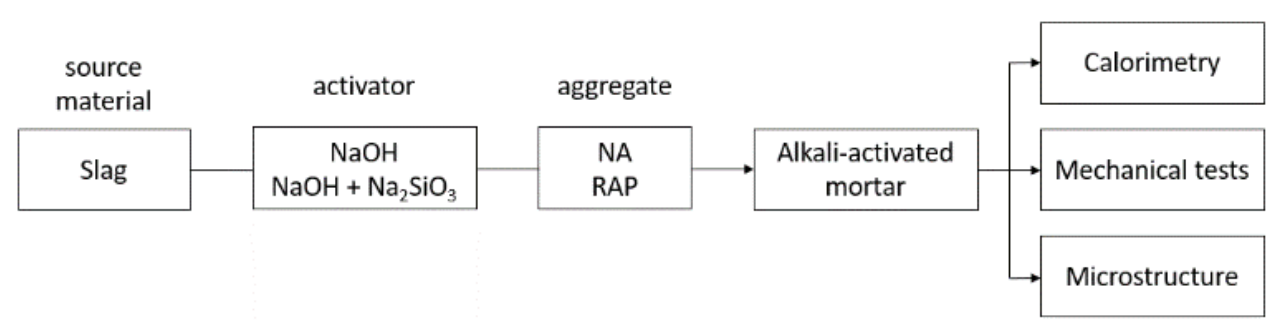

Figure 1. Research flow-chart.

\section{Experimental Program}

\subsection{Materials}

The binder used to prepare the alkali-activated mortars was a commercial ground granulated blast furnace slag (GGBFS) supplied by Ecocem (Moerdijk, The Netherlands). The chemical composition of GGBFS was determined by X-ray fluorescence (XRF) and given in Table 2 . The basicity coefficient $\left(\mathrm{CaO}+\mathrm{MgO} / \mathrm{SiO}_{2}+\mathrm{Al}_{2} \mathrm{O}_{3}\right)$ is 1.03 , and the GGBFS is therefore basic $[28,29]$.

Table 2. Chemical composition of GGBFS (XRF).

\begin{tabular}{cccccccc}
\hline \multicolumn{8}{c}{ Main Oxides (\%) } \\
\hline $\mathrm{CaO}$ & $\mathrm{SiO}_{2}$ & $\mathrm{Al}_{\mathbf{2}} \mathbf{O}_{\mathbf{3}}$ & $\mathbf{M g O}$ & $\mathrm{SO}_{3}$ & $\mathrm{TiO}_{\mathbf{2}}$ & $\mathbf{F e}_{\mathbf{2}} \mathbf{O}_{\mathbf{3}}$ & $\mathbf{M n}_{\mathbf{2}} \mathbf{O}_{\mathbf{3}}$ \\
\hline 42.68 & 37.31 & 10.38 & 6.55 & 1.49 & 0.7 & 0.36 & 0.33 \\
\hline
\end{tabular}

Figure 2 shows the mineralogical composition of GGBFS was determined by X-ray diffraction (XRD), using a Bruker D8 Advance with copper radiation (Billerica, MA, USA) (scanning at $2 \theta=1^{\circ}$ per minute, step size 0.04 ). The XRD diffractogram presents the GGBFS as a predominantly amorphous material, due to the absence of well-defined peaks. There is a single broad and diffuse peak $2 \theta \sim 32^{\circ}$; it corresponds to the short-range order of the $\mathrm{CaO}-\mathrm{Al}_{2} \mathrm{O}_{3}-\mathrm{MgO}-\mathrm{SiO}_{2}$ glass structure [30]. The particle size distribution of the GGBFS (Figure 3) was measured using a Mastersizer Hydro 2000G Particle Size Analyser (Malvern, UK) using water dispersion. The equipment is designed to carry sub-micron analysis in the range of 0.02 to $2000 \mu \mathrm{m}$. GGBFS has a medium particle size of $13.7 \mu \mathrm{m}$, which indicates that it is finely ground and therefore suitable for alkaline activation.

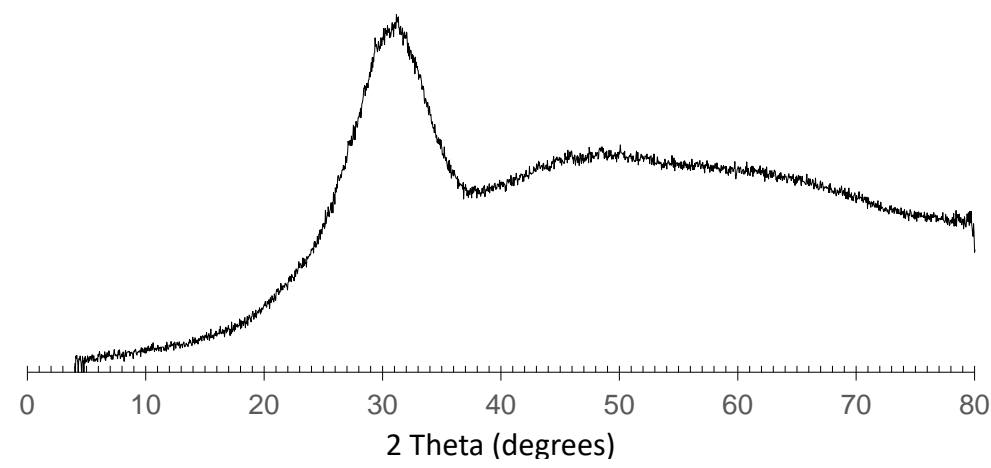

Figure 2. XRD pattern of GGBFS. 


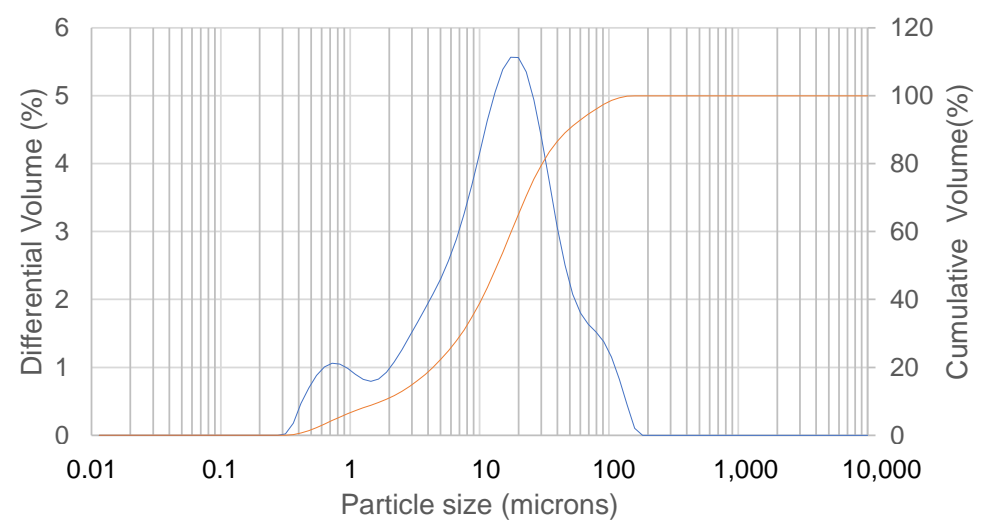

Figure 3. LASER particle size distribution of the GGBFS.

The activation of the GGBFS was carried out by an alkaline solution composed of sodium hydroxide $(\mathrm{NaOH})$, sodium silicate $\left(\mathrm{Na}_{2} \mathrm{SiO}_{3}\right)$, and demineralised water. VWR supplied the $\mathrm{NaOH}$ ( $98 \%$ pure) pellets and the $\mathrm{Na}_{2} \mathrm{SiO}_{3}$ solution with an initial composition of $25.9 \mathrm{wt} . \%$ of sodium oxide $\left(\mathrm{Na}_{2} \mathrm{O}\right), 7.9 \mathrm{wt} . \%$ of silicon oxide $\left(\mathrm{SiO}_{2}\right)$, and $66.2 \% \mathrm{H}_{2} \mathrm{O}$. The activator was prepared firstly by mixing the $\mathrm{NaOH}$ pellets with water, stirring until all pellets dissolved, and waiting approximately $24 \mathrm{~h}$ to cool down before adding the sodium silicate solution.

The fine aggregates used for the preparation of the mortars were natural fine aggregates (NA) and the fine fraction of Reclaimed Asphalt Pavements (RAP). The RAP aggregate, supplied by Willemen Infra Recycling (Kieldrecht, Belgium), was obtained from local flexible pavement. The aggregates were oven-dried at $60 \pm 2{ }^{\circ} \mathrm{C}$ for $72 \mathrm{~h}$ and sieved to remove the coarse fraction. A low drying temperature was selected to avoid melting the bitumen adhered to the particles. The aggregates particle size distribution (PSD) is presented in Figure 4 alongside the pictures of the fractions. The fineness modulus was equal to 2.82 and 4.53 for NA and RAP, respectively. The NA is a poorly graded aggregate with over $85 \%$ of its particles between 0.25 and $0.125 \mathrm{~mm}$, while RAP aggregates have a better distribution among the sieves and a coarser overall size. The RAP used in this research had its gradation curve modified to match the gradation curve of the natural sand.

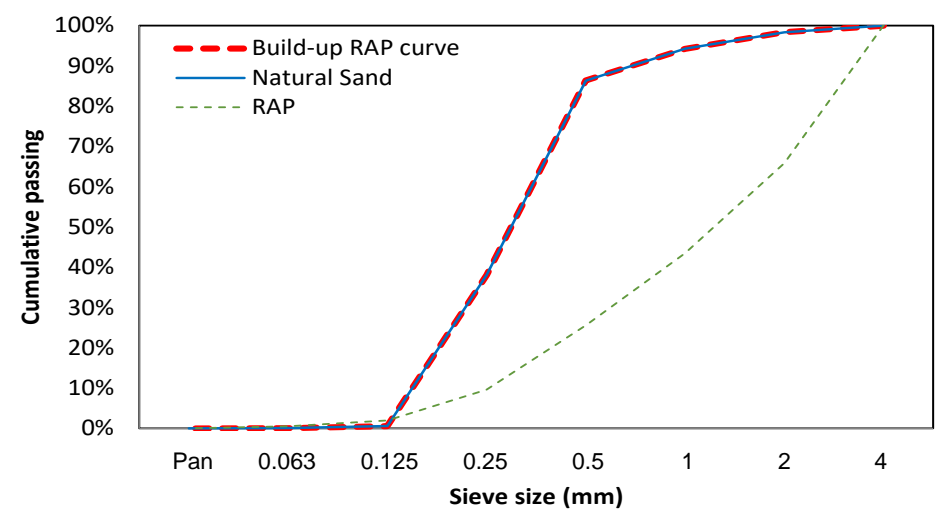

Figure 4. Aggregates particle size distribution.

The specific gravities of the aggregates used, measured by pycnometry, were 2.74 and 2.24 for NA and RAP, respectively. The bitumen content of the fine RAP fraction was determined by separating the binder using trichloroethylene solvent in a centrifuge as per the NBN EN 12697-1 [31] method and was 6.9\%.

\subsection{Specimen Preparation}

This study investigated the optimal alkali content to activate the GGBFS binder in mortars prepared with $100 \%$ RAP as aggregate. The reference samples followed an 
identical design but used $100 \%$ NA. Six different alkali solutions were used by combining $\mathrm{Na}_{2} \mathrm{O}\left(4 \%\right.$ or $6 \%$ by weight of BFS) with the modulus of silica $\left(\mathrm{Ms}=\mathrm{SiO}_{2} / \mathrm{Na}_{2} \mathrm{O}\right.$ molar ratio) in the activator, either $0,0.5$, or 1 . The dosages were select in accordance with the literature [28,32-34]. The mortar formulations had fixed water to GGBFS ratio and aggregate to GGBFS ratios, 0.5 and 1.5, respectively (Table 3). In the notation of the formulations, $\mathrm{N}$ denotes mortars made with natural aggregate and $\mathrm{R}$ using RAP. The first number shows the $\% \mathrm{Na}_{2} \mathrm{O}$, and the second (preceded by $\mathrm{M}$ ) designates the modulus of silica. For example, mortar N4M1 denotes a mortar made with natural aggregate and activated with $4 \% \mathrm{Na}_{2} \mathrm{O}$ and $\mathrm{Ms}=1$.

Table 3. Formulations studied.

\begin{tabular}{ccccc}
\hline Notation & $\mathbf{N a}_{\mathbf{2}} \mathbf{O}(\mathbf{\%})$ & Ms & Water/GGBFS & Agg./GGBFS \\
\hline N4M0, R4M0 & 4 & 0 & 0.5 & 1.5 \\
N4M0.5, R4M0.5 & 4 & 0.5 & 0.5 & 1.5 \\
N4M1, R4M1 & 4 & 1 & 0.5 & 1.5 \\
\hline N6M0, R6M0 & 6 & 0 & 0.5 & 1.5 \\
N6M0.5, R6M0.5 & 6 & 0.5 & 0.5 & 1.5 \\
N6M1, R6M1 & 6 & 1 & 0.5 & 1.5 \\
\hline
\end{tabular}

The PSD curve of the RAP aggregate was corrected to match the NA aggregate gradation so that the different PSD did not affect the results. In other words, all formulations were made with aggregates with the same PSD, given by the red and blue line in Figure 4. Before sieving, the RAP was dry mixed in a concrete mixer for $15 \mathrm{~min}$ to disaggregate the granules further.

The samples were produced using the following procedure: (i) the alkali solution and aggregates were mixed for $30 \mathrm{~s}$; (ii) the GGBFS were added during mixing for the next $30 \mathrm{~s}$; (iii) the mixing continued for the next $30 \mathrm{~s}$; (iv) the mixer was stopped to scrape the mixture off the sides of the bowl and switched on again on for $1.5 \mathrm{~min}$; (v) the samples were poured into pre-oiled moulds and compacted using a vibrating table.

All samples were kept inside the mould for $24 \mathrm{~h}$. After demoulding, the samples were placed wet, sealed inside a plastic bag under room temperature $\left(20^{\circ} \mathrm{C} \pm 4^{\circ} \mathrm{C}\right)$ until testing.

\section{Testing Procedures}

An isothermal calorimeter (TAM air, TA Instruments, New Castle, DE, USA) was used to investigate the influence of RAP aggregates on the reaction kinetics of the alkali-activated binders. The equipment was set at a constant temperature of $20^{\circ} \mathrm{C}$. Approximately $15 \mathrm{~g}$ of mortar were mechanically mixed inside the glass ampoule for $1.5 \mathrm{~min}$. The ampoule containing the mortar was placed inside the calorimeter $3 \mathrm{~min}$ after the mixing procedure initiation. The heat production was recorded for seven days.

The flexural strength and compressive strength of the samples were measured at 1,3 , 7, 28 and 60 days following NBN EN 196-1 [35]. Three prismatic samples $(4 \times 4 \times 16 \mathrm{~cm})$ were used at each age. The samples were kept sealed at room temperature and were tested at 1, 3, 7, 28 and 60 days. All samples were first tested for flexural strength, followed by compressive strength recommended by the standard method.

Mercury Intrusion Porosimetry (MIP) assessed the pore size distribution using a Quantachrome PoreMaster-60, with low pressure ranging from 1.5 to $300 \mathrm{kPa}$ and high pressure from $140 \mathrm{kPa}$ to $420 \mathrm{MPa}$. The study assumed a contact angle of $140^{\circ}$ and the surface tension of mercury of $0.48 \mathrm{~N} / \mathrm{m}$. Thin slices of the centre of the samples were sawed (about $2 \mathrm{~mm}$ thick) and dried at $60^{\circ} \mathrm{C}$ for $72 \mathrm{~h}$ before testing. This drying regime did not degrade (melt) the bitumen layer on the surface of the RAP aggregates.

The microstructure characterisation was carried out by Scanning Electron Microscopy (SEM) on Backscattering Electron Image mode and Confocal Laser Scanning Microscopy (CLSM). Herein SEM was performed on a Hitachi TM3000 benchtop microscope (Boynton Beach, FL, USA) to assess the porosity of samples mainly at the interface transition zone 
(ITZ) between AAM matrices and NA or RAP aggregates. A Keyence VK-X1000 Confocal Microscope (Osaka, Japan) was first used to assess the particle shape of both aggregates (natural and RAP) and determine the amount of bitumen covering the RAP particles quantitatively. The latter was calculated by image analysis after treatment of 3 stitched CLSM images (corresponding to 49 images) with the software ImageJ. CLSM was also employed on cut and broken samples of selective mortar formulations to assess the ITZ between matrix and aggregates. The samples for SEM were mounted on an epoxy resin and later ground using a sequence of $\mathrm{SiC}$ paper and polished with diamond paste.

\section{Results and Discussion}

\subsection{Isothermal Calorimetry}

Figures 5 and 6 present the results of the isothermal calorimetry when, respectively, natural aggregates and RAP aggregates were employed. All mortars showed a sharp main peak at the beginning of the curve $(60 \pm 10 \mathrm{~min}$ of testing. This reaction is only partially captured due to the time it takes to mix, load, and equilibrate the sample in the instrument. After the initial peak, the samples prepared without silicates (N4M0 and N6M0) show an almost immediate second increase in heat flow, while the samples with silicates (N4M1 and N6M1) show a slow reduction before the next flow peak.

The complex mechanism involved in the alkaline activation of GGBFS is not yet fully understood and is often summarised firstly as the breakdown of the structure, followed by polycondensation and precipitation of the reaction products $[36,37]$. The heat evolution of GGBFS can be described in five steps. There is a sharp peak at the first few minutes of the reaction associated with the partial dissolution of the slag. It is followed by an induction period with low reactivity until the next peak. The second peak comprises the third and fourth step, called acceleration and deceleration, where massive precipitation of the reaction products occurs. The final step is called decay, and it is a low reactivity period until the end of the reaction $[36,38]$.

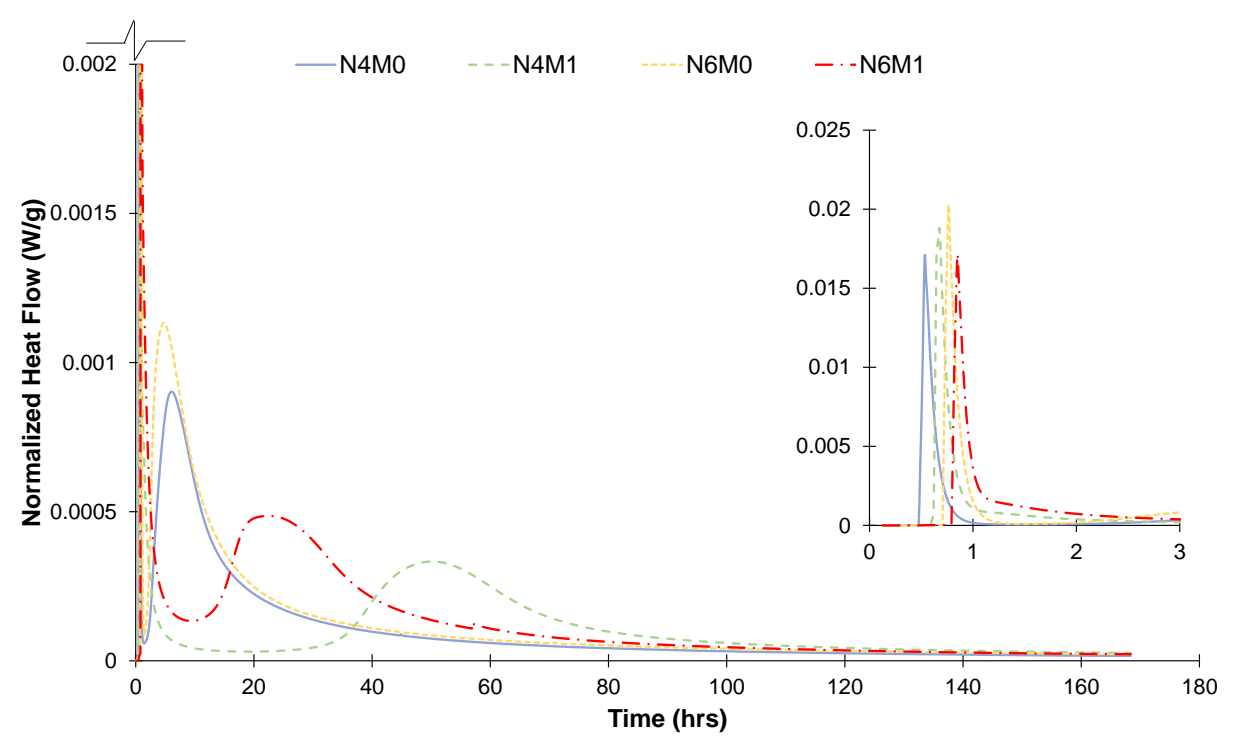

Figure 5. Effect of activators on heat evolution of natural aggregate mortars. 


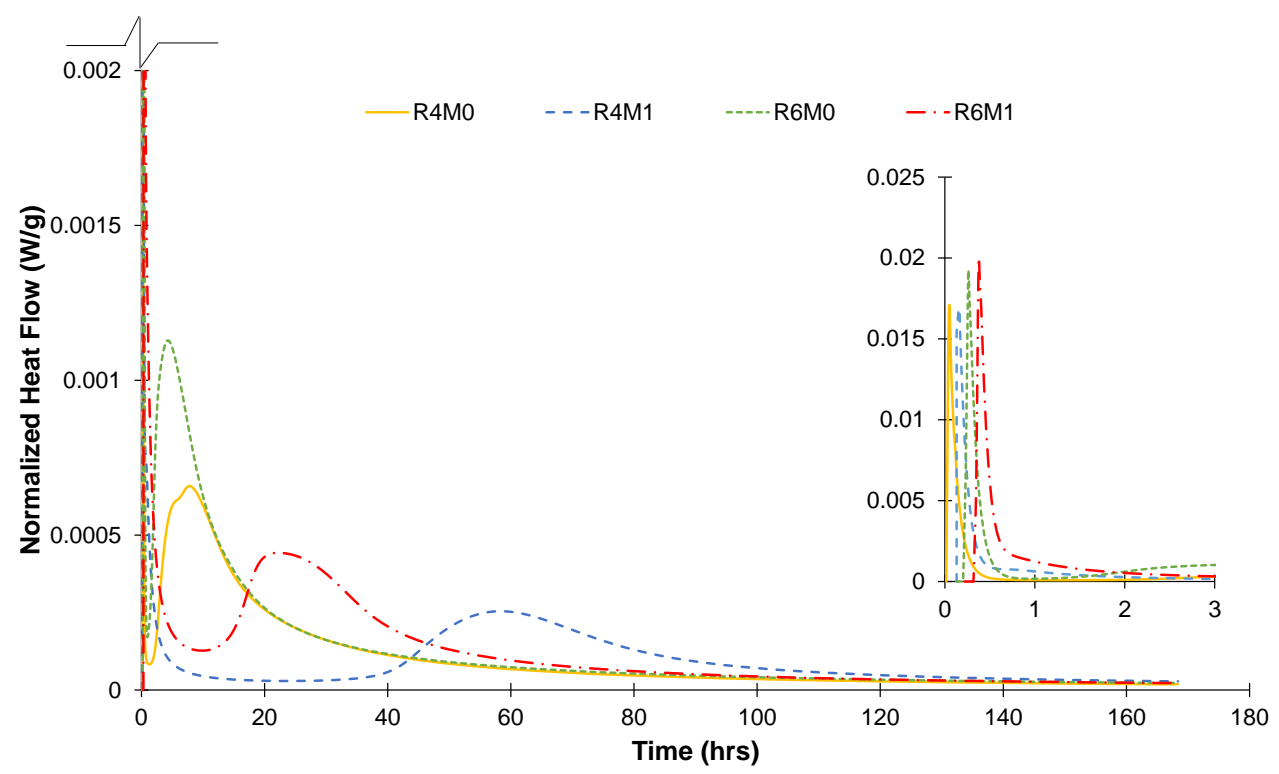

Figure 6. Effect of activators on heat evolution of RAP aggregate mortars.

The type of alkalis used in the activator has an important role in each of the steps. The high intensity at the beginning of the reaction and the impact of the sample preparation make it difficult to detect and compare the first peak. The effect of the activators on steps two to five can be seen more clearly.

When the activator is $\mathrm{NaOH}$ (samples $\mathrm{N} 4 \mathrm{M} 0$ and N6M0), the induction period is extremely short, and the second peak of the curve (associated with the formation of hydrated products such as C-A-S-H gel) is more intense and shorter in duration [36,39,40]. Samples with sodium silicate (N4M1 and N6M1) show a delayed second peak (after the induction period) that is correlated to the workability retention typically from the employment of waterglass [39]. In both systems $\left(\mathrm{NaOH}\right.$ or $\left.\mathrm{NaOH}+\mathrm{Na}_{2} \mathrm{SiO}_{3}\right)$, the induction period is greatly reduced by increasing sodium oxide, which aligns with previous research $[37,40]$. The peaks are also higher when more $\mathrm{Na}_{2} \mathrm{O}$ is used if comparing curves N6M1 with N4M1, and N6M0 with N4M0. This indicates that the $\mathrm{OH}^{-}$has an accelerating effect on the dissolution and hydration of the slag [37].

When natural aggregates are replaced with RAP particles (Figure 6), the heat evolution of the samples follows a similar trend. This result indicates that the bitumen coating on the RAP aggregates does not alter the hydration reaction of the alkali-activated binder. Figure 7 summarises the cumulative heat of all formulations, and it is a better way to show some minor differences between the curves with NA and RAP, which can be attributed to the higher heat capacity of bitumen. In other words, bitumen has a high heat capacity; thus, RAP containing mortars yields a smaller temperature rise compared with NA-mortars. Similar results were observed with RAP aggregates on Portland cement matrices [41,42].

The higher $\mathrm{Na}_{2} \mathrm{O}$ content ( $6 \%$ wt. against $4 \%$ wt. slag) generates more heat during the activation, irrespective of the type of aggregate used (Figure 7). The effect on mechanical performance will be discussed in the following section. 


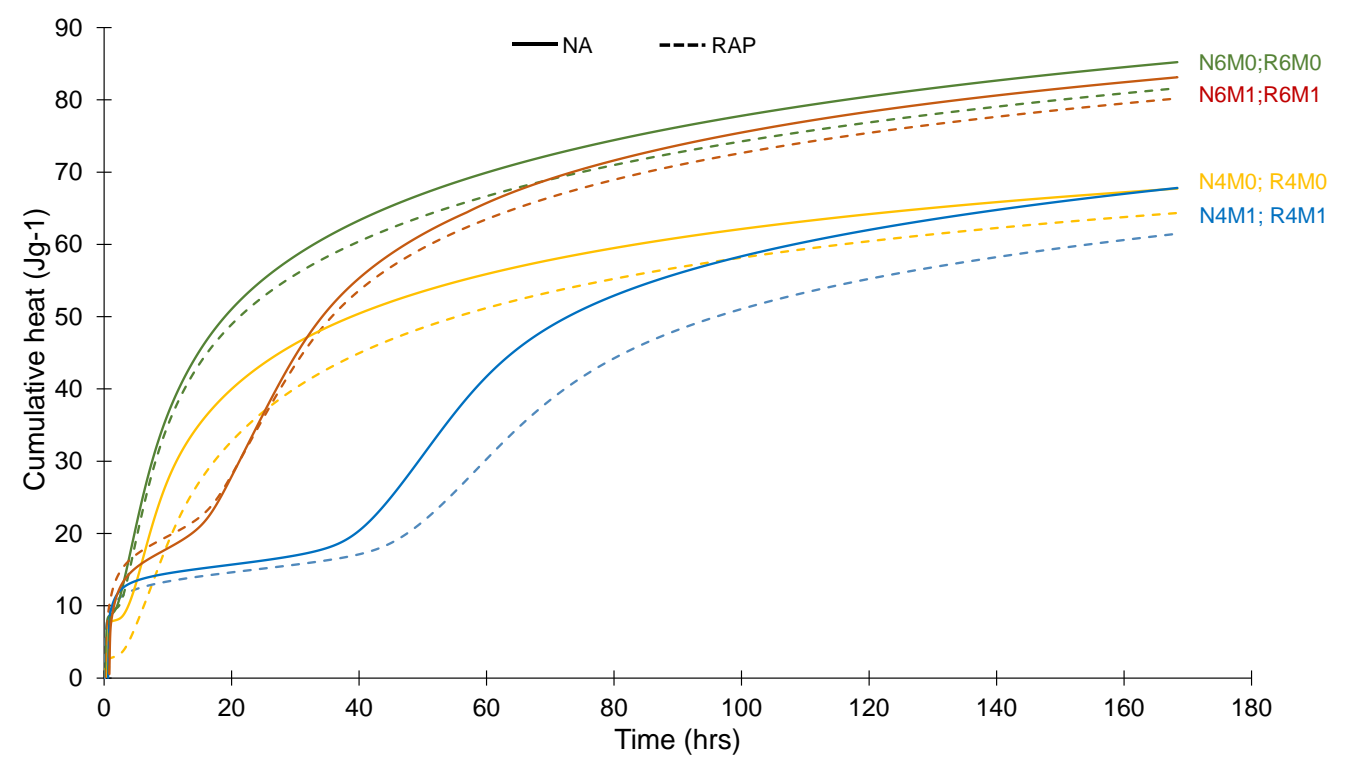

Figure 7. Cumulative heat of alkali-activated samples.

\subsection{Compressive and Flexural Strength}

Figure 8 shows the average results for compressive strength of the mortars produced with NA and RAP, while Figure 9 shows the flexural strength results. The error bars indicate the standard deviation. The mortars containing RAP aggregates are represented as hatched bars alongside its counterpart mortar made with natural aggregates as a solid bar.

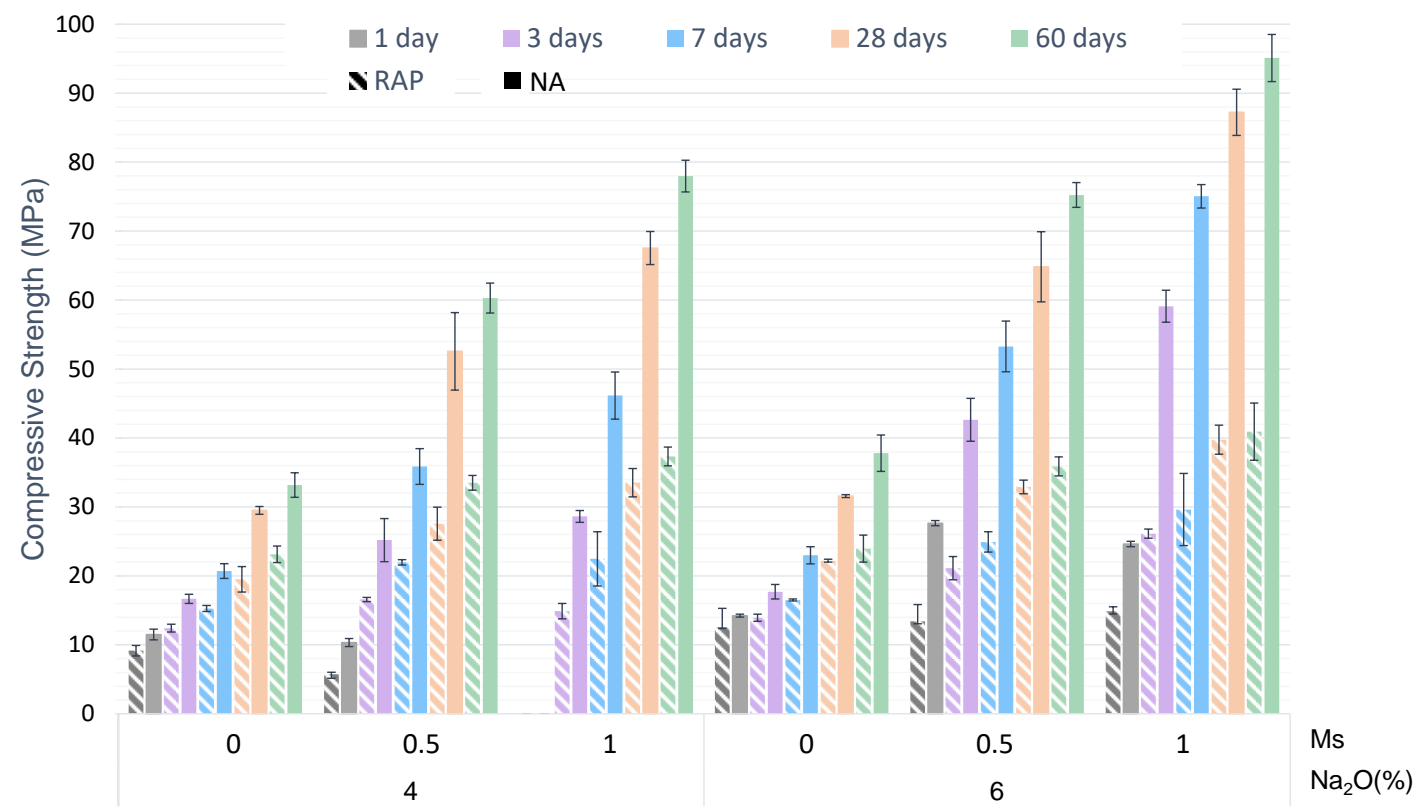

Figure 8. Compressive strength of mortars. 


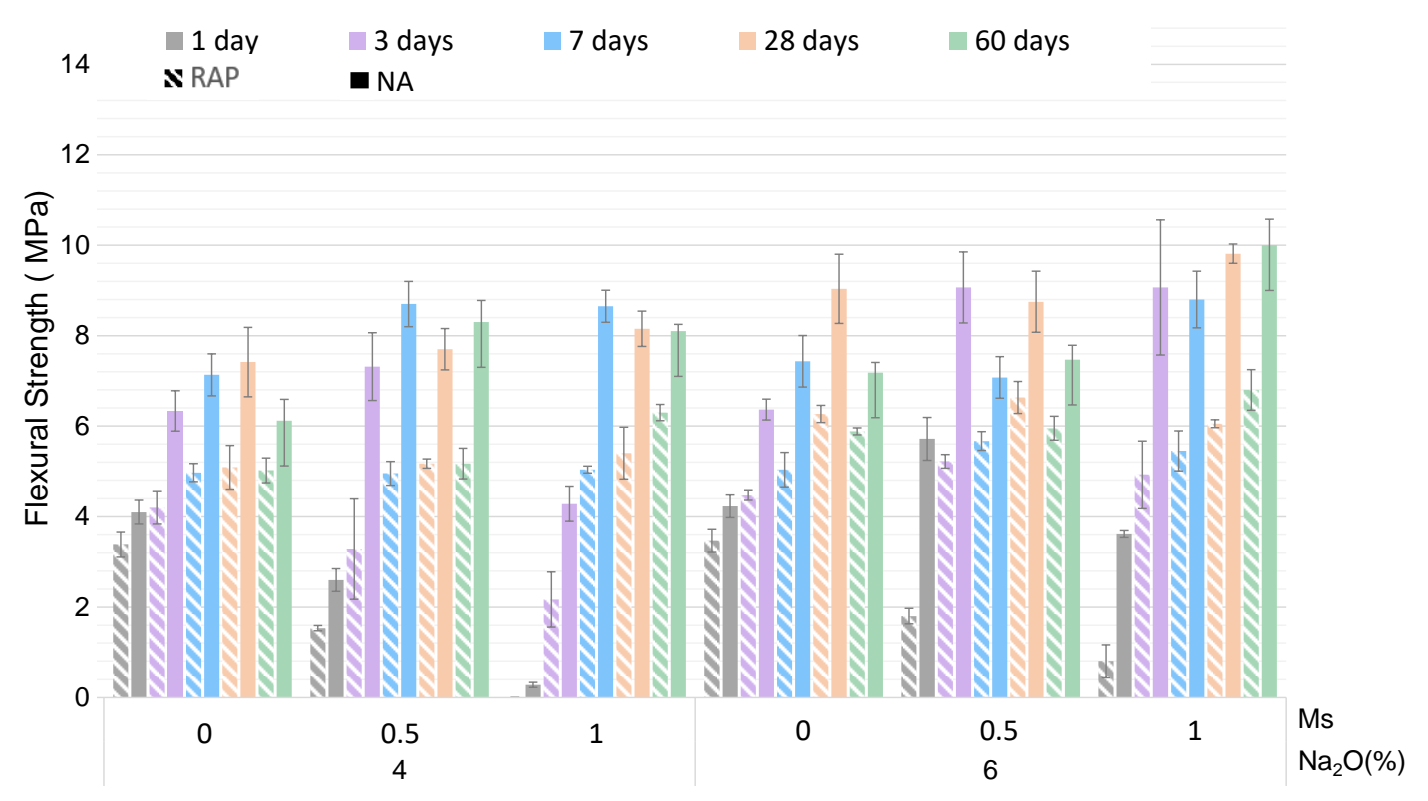

Figure 9. Flexural strength of mortars.

It is possible to notice that the increase in $\mathrm{Na}_{2} \mathrm{O}$ from $4 \%$ to $6 \%$ had a negligible impact on flexural and compressive strength at all ages when $\mathrm{Ms}=0(\mathrm{NaOH}$-activated formulations). Wang et al. [28] studied neat $\mathrm{NaOH}$-activated slags; they concluded that above a certain value of $\mathrm{Na}_{2} \mathrm{O} \%$, it is not recommended to increase the alkali dosage as it will not bring any significant increase in strength and might be followed by some negative properties such as efflorescence and brittleness. According to Komnitsas and Zaharaki [43], $\mathrm{KOH}$-activated slag in the absence of silicates takes longer to solidify, and an increase in the alkali concentration will not bring significant changes to the compressive strength (will not exceed $25 \mathrm{MPa}$ at two days).

A better strength performance from the combined source of activation (sodium silicate + sodium hydroxide) is in accordance with the literature [34,44]. At later ages (7 and 28 days), there is a significant increase in compressive strength with sodium silicate-the more sodium silicate used, the higher the compressive strength results (Figure 9). However, the addition of sodium silicate (Ms $>0$ ) does not have a positive effect at early ages (1 day) for all mixes. GGBFS activated with $\mathrm{Na}_{2} \mathrm{O}=4 \%$, and $\mathrm{Ms}=1.0$ did not sufficiently react for the 1-day assessment, while the others showed a slight increase in compressive strength.

The increase in activator dosages was less significant (15 to $43 \%$ lower at 28 days) on flexural strength on mortars produced with both NA and RAP (Figure 9). Ageing also played a less important role, as after three days, the results showed little difference (taking into account the standard deviation). The high standard deviation of the samples is likely due to flaws in the mortars paste, such as air-entrained pores. These flaws allow for the propagation of cracks and compromise the results. The apparent decrease in flexural strength at 60 days is likely to be related to that.

The substitution of NA for RAP caused a significant reduction in both the compressive and flexural strength of the mortars. A similar result was reported for Portland cement (Xijun Shi, 2020; Sarah Mariam Abraham, 2018) and alkali-activated (Nabil Hossiney, 2020) matrices. The RAP aggregates compromised samples' ability to develop strength over time; it is possible to observe that the difference in strength between the NA-based and the RAP-based mortars increases as the age of the samples. The addition of sodium silicate promotes a rise in compressive strength, but this is less significant for RAP-AAM. Figure 10 shows the impact of increasing the Ms ratio on compressive strength gain and loss. In this figure, $0 \%$ represents the strength found for $\mathrm{Ms}=0$. In general, adding sodium silicate to the RAP systems had half of the effect on compressive strength compared with NA systems. 
For example, the 28 days compressive strength of NA-based mortar rose $178 \%$ when the Ms ratio increased from 0 to 1 (at 6\% $\mathrm{Na}_{2} \mathrm{O}$ ), the RAP-mortar increased 79\%.

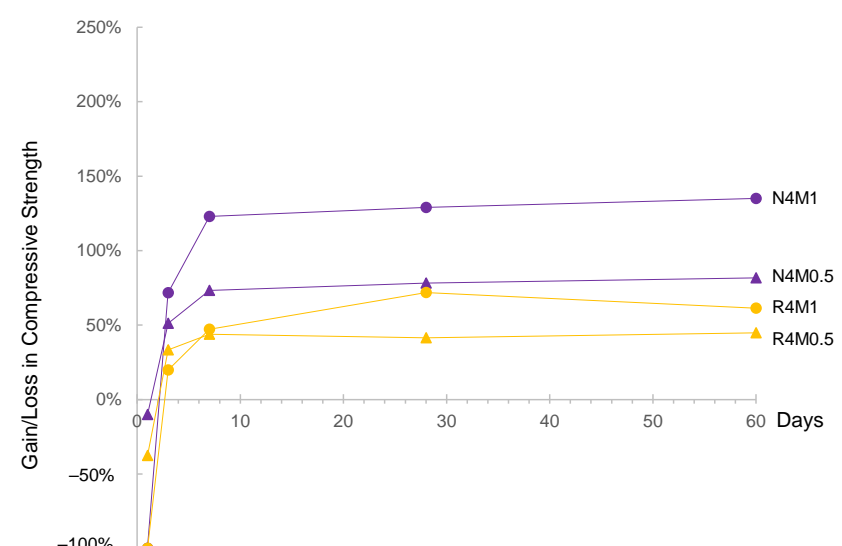

(a)

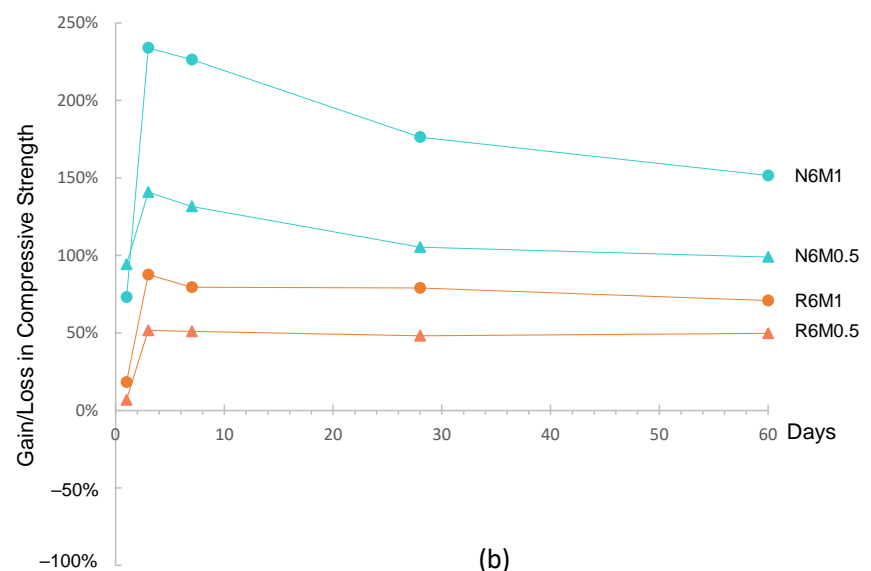

(b)

Figure 10. Gain and Strength loss in compressive strength due to the increase in Ms for (a) mortars with $4 \% \mathrm{Na}_{2} \mathrm{O}$ (b) mortars with $6 \% \mathrm{Na}_{2} \mathrm{O}$.

The inability of RAP-mortars to gain strength compared with NA-mortars is likely due to the binding between aggregates and binder and will be further discussed in Section 4.4.

Despite the reductions in strength, it is possible to observe that RAP mortars presented sufficient compressive strength even for pavement layers (i.e., higher than $20 \mathrm{MPa}$ at 28 days). The use of sodium silicate should be kept to a minimum or avoided since it has limited efficiency. RAP coarse aggregates may further improve the strength if aiming for a lean concrete base course in semi-rigid pavements or surface layers in rigid pavement.

\subsection{Mercury Intrusion Porosimetry (MIP)}

Figure 11presents the results of pore size distribution via MIP. It is important to highlight that this technique has some shortcomings-mainly high-pressure intrusion that may alter the microstructure of cementitious materials and assumptions that the pores are cylindrical [45]. Because of that, small variations in formulations might not be detected using MIP. Nevertheless, the latter has been extensively used to characterise cement-based materials, including AAM [46-48]. The results presented in Figure 11 are for four formulations (N4M0, R4M0, N4M1 and R4M1). Therefore, the effect of the type of the aggregate and presence of sodium silicate can be discussed.

It is possible to see that the total MIP porosity of the activated mortars increased with the substitution of natural aggregates with RAP and decreased slightly with soluble silicates (Figure 11a). This finding is in accordance with the compressive strength findings-the use of soluble silicates increases the compressive strength of the samples while the substitution of RAP decreases. The lower porosity and higher strength of the mortar samples in the presence of silicates are attributed to a higher degree of GGBFS activation, thus forming a denser pore structure [49].

The cumulative intrusion curves (Figure 11b) have a different shape according to the types of aggregate used. The mortars containing RAP (orange and light green curves) have coarse porosity, with more than $20 \%$ pores above $100 \mu \mathrm{m}$. The cumulative curves did not change much for different Ms in the activator (M0 and M1), which shows that the type of the aggregate affects more the pore size distribution than the matrix.

Pore distribution (Figure 11c,d) showed a predominance of micropores $(<0.1 \mu \mathrm{m})$, $59.0 \%$ and $53.5 \%$, respectively, for $\mathrm{R} 4 \mathrm{M} 0$ and R4M1 and 79.5\% and $82.9 \%$, for N4M0 and N4M1. The significant increase in macropores $(>10 \mu \mathrm{m})$ for RAP mortars is confirmed, i.e., $28.7 \%$ and $37.9 \%$ against $6.2 \%$ and $10.5 \%$ for mortars with NA (Figure $11 \mathrm{~d}$ ). The increased presence of macropores can be attributed to both air entrapment and increased porosity of the ITZ. The first could indicate that RAP confers a better performance in freezing 
and thawing and salt decay [47]. The latter explains the reductions in the mechanical performance of RAP mortars discussed in Section 4.2.

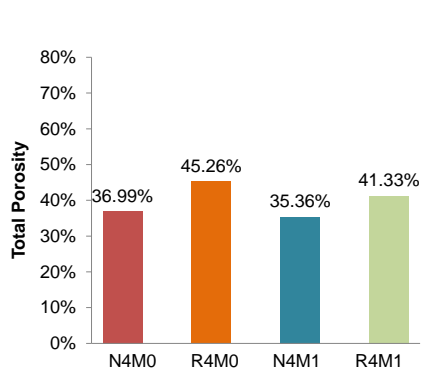

(a)

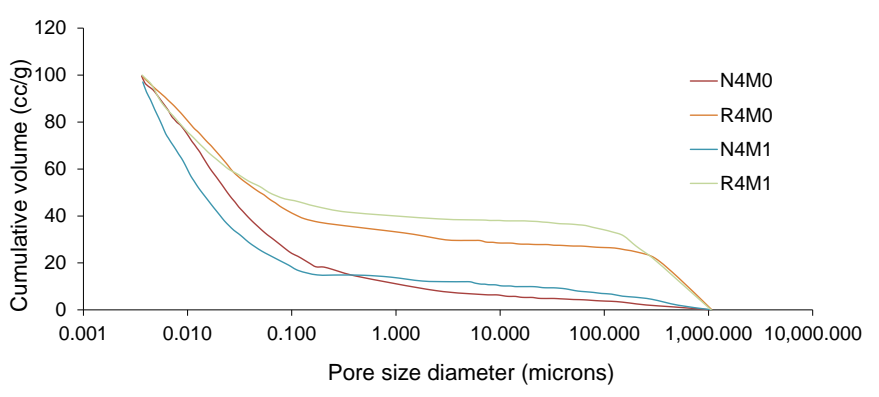

(b)
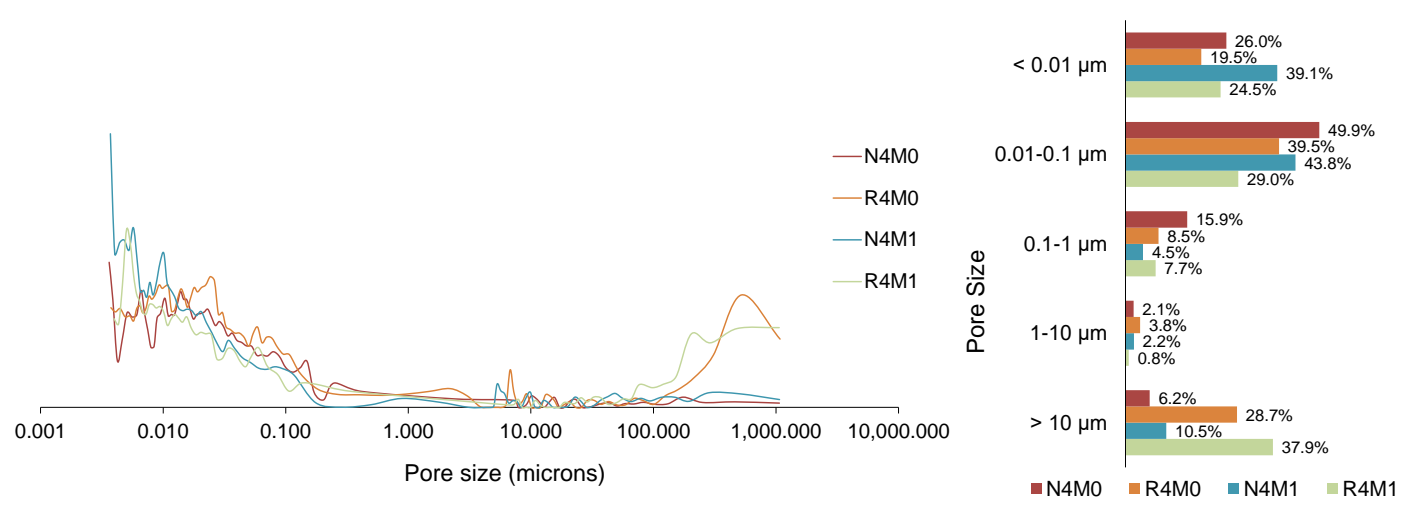

Figure 11. MIP results: (a) total porosity, (b) cumulative intrusion curve, (c,d) pore size distribution.

\subsection{Microstructure Observation of the Mortars (SEM and CLSM)}

Figure 12 shows the aggregate particles used in this research, as visualised by CLSM. The natural aggregates (Figure 12a) have a round shape, while the RAP aggregates (Figure 12b) are slightly angular. There is a significant difference in each RAP grain; some are heavily coated (such as the one inside the red circles), while others have little or no bitumen (highlighted by an arrow). The heavily coated grains also seem to be formed by a cluster of smaller particles bonded by the bitumen. The image analysis (Figure 13) resulted in an average of $72.9 \%( \pm 9.6 \%)$ RAP particles covered by bitumen.

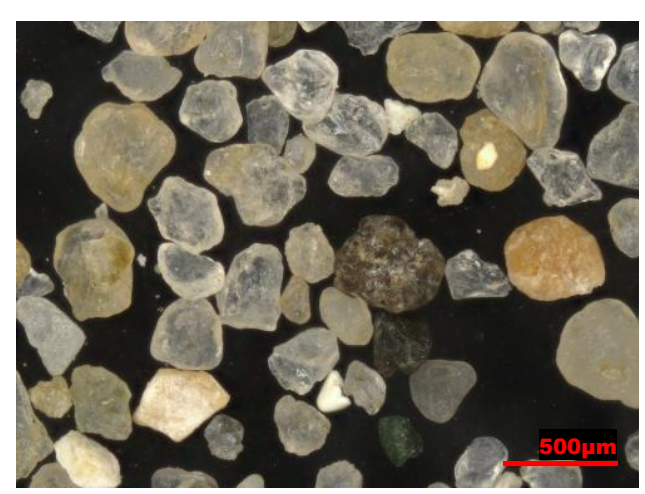

(a)

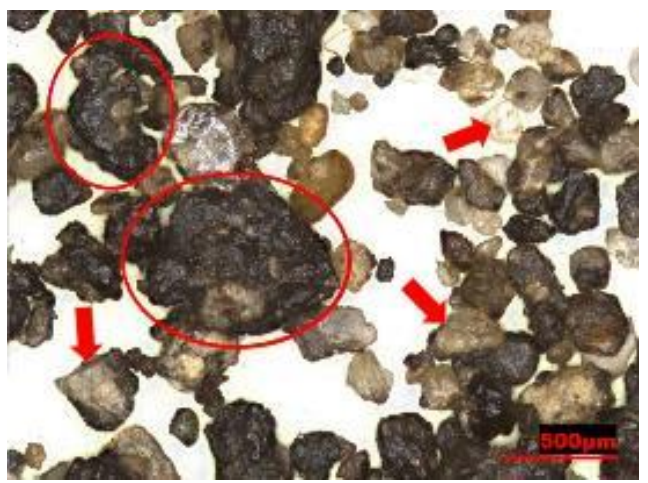

(b)

Figure 12. Fine aggregates (a) natural (b) RAP. 


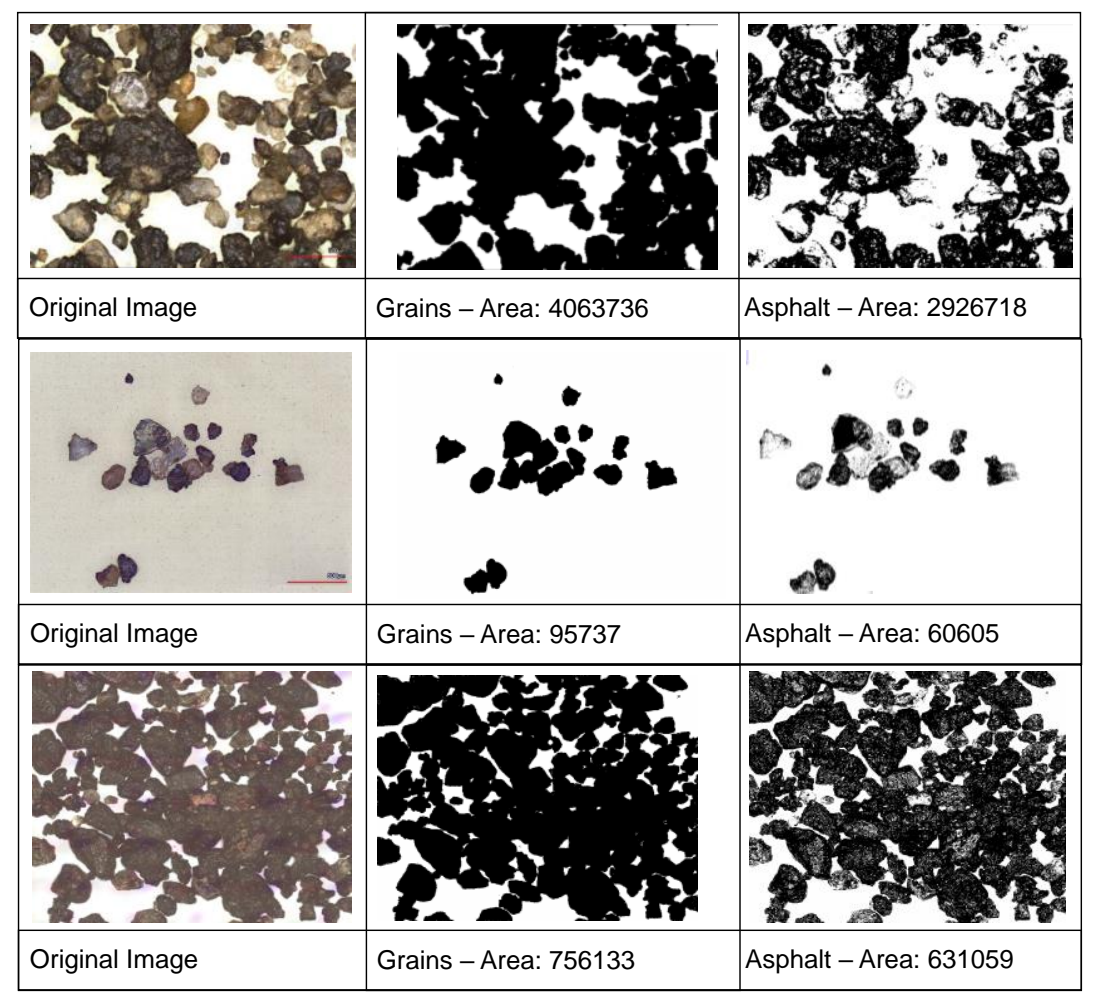

Figure 13. ImageJ analysis of bitumen content of the RAP grains.

Figure 14 shows the images obtained for sample N4M0. From the sawed sample (Figure 14a), it is possible to observe the aggregate clusters and note the large quantities of bitumen adhered to the grains, while other sections show only the bitumen with little to no aggregates. RAP-AAM is a composite material and the interaction between each constituent determine the mechanical behaviour of the mortar. The presence of clusters of aggregates formed with large quantities of bitumen should have a great impact on the final strength of the material. These clusters may reduce the strength of the composite, since bitumen has inferior mechanical properties compared with natural aggregates.
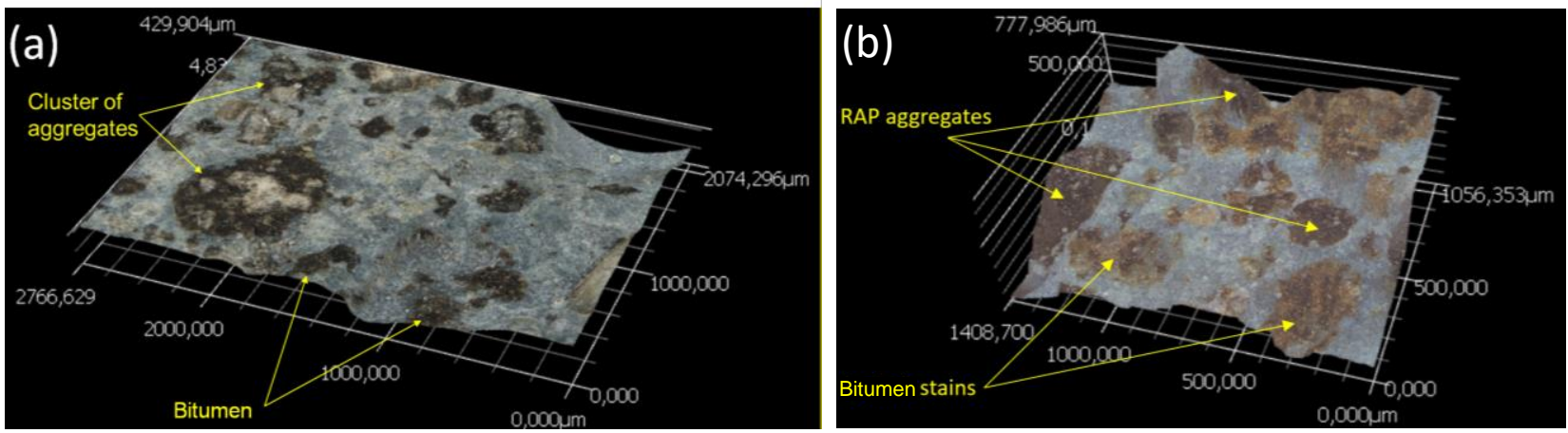

Figure 14. R4M0 (a) sawed, (b) broken.

The broken sample (Figure 14b) has a more irregular surface, and also part of the bitumen appears dissolved into the matrix. This image shows, in particular, that the fracture of the specimens predominantly happened at the interface with the bitumen layer. This suggests that the poor adhesion between aggregates and bitumen could also be responsible for the reduced compressive strength when RAP is used.

The clear distinction between the matrix, aggregates and bitumen, and their distribution in the microstructure is a special feature that CLSM allows in the characterisation 
of RAP-based composites. This distinction is not so evident in SEM. On the other hand, CLSM presents poor interface transition zone images (ITZ); the latter is better analysed via SEM.

Secondary backscattered electron images on SEM of the mortars incorporating NA and RAP aggregates are shown in Figures 15 and 16. It is possible to observe the large aggregate grains and the alkali-activated matrix containing unhydrated slag particles. Figure 15a,b shows, respectively, for NA and RAP, the interface between aggregates and the matrix. It is possible to observe a negligible increase in porosity at the interface between the NA aggregates and the matrix in Figure 15a. In other words, the ITZ is not clear and easy to delineate (see dashed lines) in NA-based AAM. On the contrary, ITZ is easy to identify in Figure 15b; it is much enlarged and more porous when NA is replaced by RAP, which was also observed by [50] for Portland cement-based matrices. The worsening of the ITZ may explain the high porosity and the loss in strength observed in Section 4.2. For the latter, two explanations are possible: the bitumen coating reduces the roughness of the aggregates (and consequently the physical interlocking) and hinders any chemical bonding that might occur between matrix and aggregate [42].

Figure 16 shows the cracking pattern of the samples. Images (a) and (b) were taken from samples with NA and samples (c) and (d) with RAP. The alkaline solution of samples (a) and (c) contained only $\mathrm{NaOH}$, while samples (b) and (d) had also sodium silicate. All samples showed cracking around aggregate particle with connections to the activated slag paste. The cracking pattern has increased at the presence of sodium silicate; however, it is not possible to observe any increase in cracking with the employment of RAP aggregates. The presence of microcracks in transition zones of RAP and OPC matrices was observed by $[51,52]$. Alkali-activated slag matrices are known for having higher shrinkage than PC matrices [53]. However, it is unclear if the cracks observed result from the higher shrinkage of the matrix or if it is due to the sample's preparation.
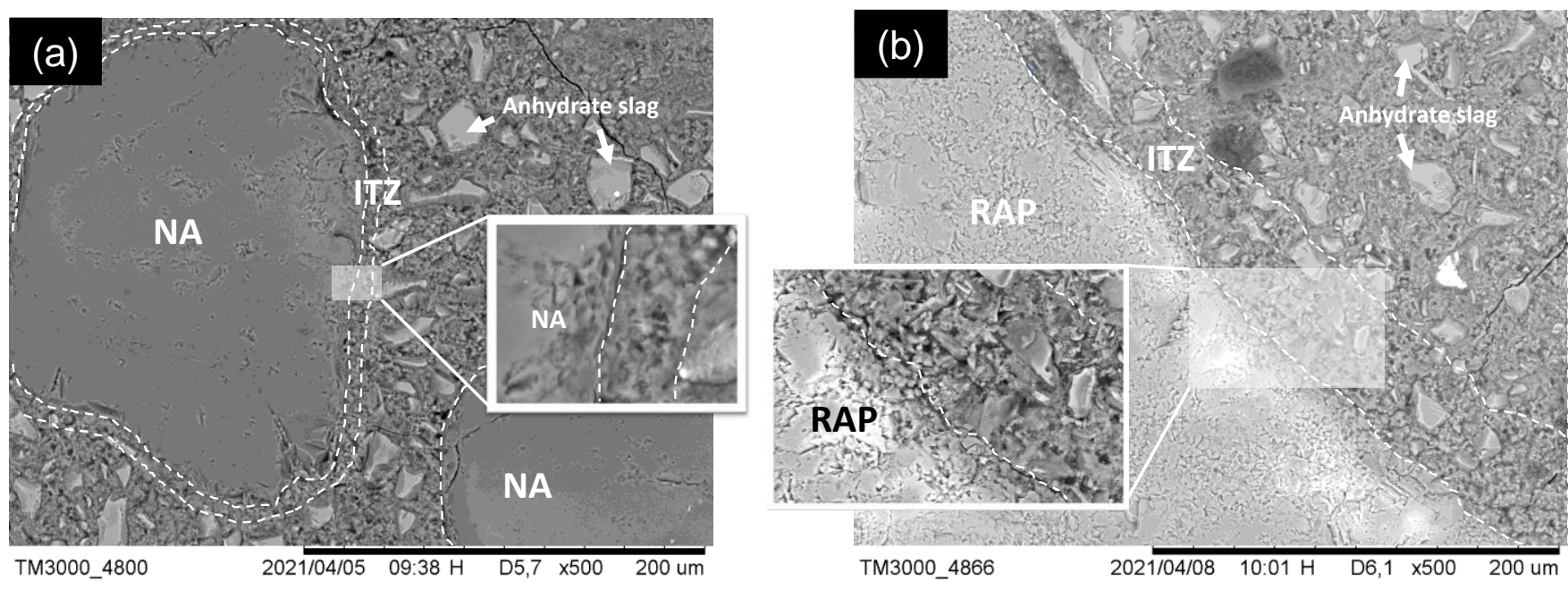

Figure 15. SEM Images (a) N4M1, (b)R4M1. 

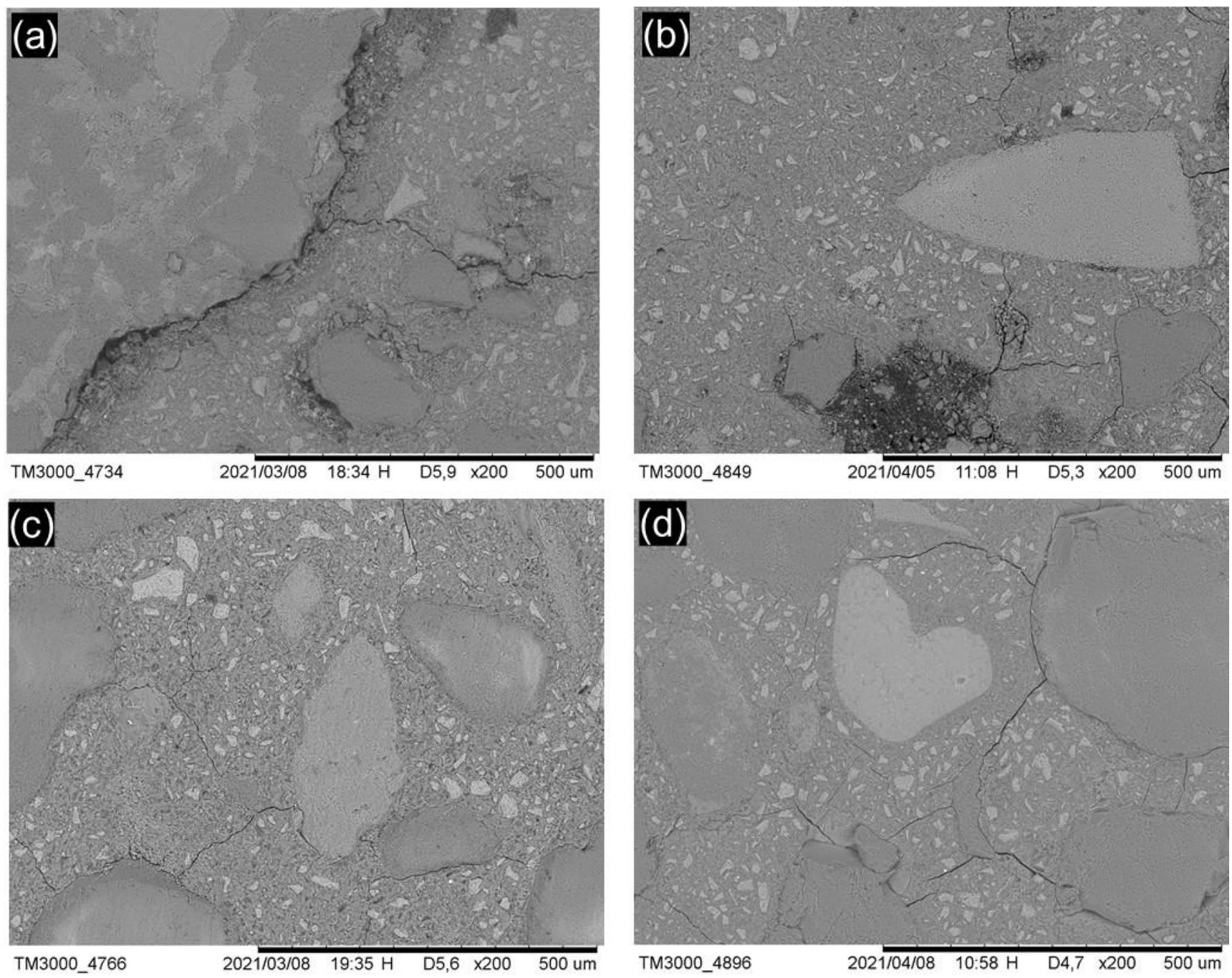

Figure 16. Evolution of cracking (a) N6M0, (b)N6M1, (c)R6M0, (d) R6M1.

\section{Conclusions}

This paper studied the effect of different activator dosages on the properties and microstructure of RAP - alkali-activated slag mortars (AAM). Natural aggregates (NA) were used as a reference. The following conclusions can be taken:

- The calorimetry studies showed that $4 \%$ to $6 \% \mathrm{Na}_{2} \mathrm{O}$ (wt. slag) content in the activator increased the heat output of all studied AAM. The presence of RAP aggregates and the bitumen coating of the RAP particles did not compromise the reaction of the matrices.

- The substitution of NA by RAP caused a significant reduction in both the compressive and flexural strength of the mortars-on average, $44 \%$ and $31 \%$ at 28 days, respectively. The RAP aggregates compromised samples' ability to develop strength over time.

- The addition of sodium silicate promotes a rise in compressive strength, but this is less significant for RAP-AAM. While the compressive strength of NA mortars increased up to $234 \%$ with sodium silicate, the strength of RAP mortars increased a maximum of $88 \%$.

- MIP results showed that samples prepared with RAP aggregates contained up to $9.3 \%$ more pores than samples prepared with NA. The pore content increase was concentrated in the macropores $(>10 \mu \mathrm{m})$. As pores' presence is directly related to strength, these findings explain the loss in strength caused by recycled aggregates (RAP). A better mix design with more fines or a pre-treatment of RAP particles should be investigated to overcome this. 
- Confocal Laser Scanning Microscopy (CLSM) is a helpful tool to identify the bitumen layers and their irregular distribution among the RAP aggregates. Some RAP particles have extremely little to no bitumen, whereas others (particularly the clusters) had an extremely high bitumen concentration. CLSM is also important to visualise the RAP distribution in the AAM mortars (sawed samples). This technique also presents evidence that the broken samples fractured at the bitumen layer, suggesting poor adhesion between aggregates and bitumen. This is linked to the reduced mechanical performance. SEM is preferable to see the interface between aggregates and matrices and confirmed that RAP-AAM contains a larger and porous ITZ than NA-AAM.

- Overall, it is possible to conclude that, although silicates increase the alkaline activation, it has little or no impact on the adhesion between aggregate and bitumen. Therefore, soluble silicates should be limited to low quantities in RAP-AAM. Any improvements in the matrix are unlikely to avoid adhesion issues that compromise the mechanical performance. Despite the reduction in strength caused by the increased porosity and poor binding to the matrix, it is still possible to achieve sufficient strength with RAP-AAS for many engineering applications.

Author Contributions: Conceptualization J.B. and W.V.d.b., formal analysis and investigation, J.O.C.; writing-original draft preparation, J.O.C. and P.H.R.B.; writing-review and editing, J.B. and W.V.d.b.; supervision, F.A.d.S.; A.C.S.B., J.B. and W.V.d.b. All authors have read and agreed to the published version of the manuscript.

Funding: This research was financed in part by Coordenação de Aperfeiçoamento de Pessoal de Nível Superior Brazil (CAPES) [Finance code 001]; and DOCPRO1 Project 42476 UAntwerp, Universiteit Antwerpen, Faculty of Applied Engineering (research group EMIB)- [Finance code 001.BOF].

Institutional Review Board Statement: Not applicable.

Informed Consent Statement: Not applicable.

Data Availability Statement: Not applicable.

Acknowledgments: The authors would like to thank Ecocem (The Netherlands) for the supply of raw materials.

Conflicts of Interest: The authors declare no conflict of interest.

\section{References}

1. EAPA Asphalt in Figures 2007. Available online: https:/ / eapa.org/asphalt-in-figures / (accessed on 30 January 2020).

2. Zaumanis, M.; Mallick, R.B.; Frank, R. 100\% recycled hot mix asphalt: A review and analysis. Resour. Conserv. Recycl. 2014, 92, 230-245. [CrossRef]

3. Arshad, M.; Ahmed, M.F. Potential use of reclaimed asphalt pavement and recycled concrete aggregate in base/subbase layers of flexible pavements. Constr. Build. Mater. 2017, 151, 83-97. [CrossRef]

4. Ullah, S.; Tanyu, B.F. Methodology to develop design guidelines to construct unbound base course with reclaimed asphalt pavement (RAP). Constr. Build. Mater. 2019, 223, 463-476. [CrossRef]

5. Avirneni, D.; Saride, S. Durability Studies on Fly Ash Stabilized Reclaimed Asphalt Pavement Materials. In Proceedings of the Geo-Chicago 2016, Chicago, IL, USA, 14-18 August 2016; American Society of Civil Engineers: Reston, VA, USA, 2016; pp. 546-555. [CrossRef]

6. Arulrajah, A.; Piratheepan, J.; Disfani, M.M. Reclaimed asphalt pavement and recycled concrete aggregate blends in pavement subbases: Laboratory and field evaluation. J. Mater. Civ. Eng. 2014, 26, 349-357. [CrossRef]

7. Adhikari, S.; Khattak, M.J.; Adhikari, B. Mechanical characteristics of Soil-RAP-Geopolymer mixtures for road base and subbase layers. Int. J. Pavement Eng. 2018, 21, 1-14. [CrossRef]

8. Consoli, N.C.; Pasche, E.; Specht, L.P.; Tanski, M. Key parameters controlling dynamic modulus of crushed reclaimed asphalt paving-powdered rock-Portland cement blends. Road Mater. Pavement Des. 2018, 19, 1716-1733. [CrossRef]

9. Poltue, T.; Suddeepong, A.; Horpibulsuk, S.; Samingthong, W.; Arulrajah, A.; Rashid, A.S.A. Strength development of recycled concrete aggregate stabilized with fly ash-rice husk ash based geopolymer as pavement base material. Road Mater. Pavement Des. 2019, 21, 1-12. [CrossRef]

10. Avirneni, D.; Peddinti, P.R.T.T.; Saride, S. Durability and long term performance of geopolymer stabilized reclaimed asphalt pavement base courses. Constr. Build. Mater. 2016, 121, 198-209. [CrossRef] 
11. Singh, S.; Ransinchung, G.D.; Debbarma, S.; Kumar, P. Utilization of reclaimed asphalt pavement aggregates containing waste from Sugarcane Mill for production of concrete mixes. J. Clean. Prod. 2018, 174, 42-52. [CrossRef]

12. Hoy, M.; Horpibulsuk, S.; Arulrajah, A.; Mohajerani, A. Strength and microstructural study of recycled asphalt pavement: Slag geopolymer as a pavement base material. J. Mater. Civ. Eng. 2018, 30. [CrossRef]

13. Provis, J.L. Alkali-activated materials. Cem. Concr. Res. 2018, 114, 40-48. [CrossRef]

14. Provis, J.L.; Bernal, S.A. Geopolymers and related alkali-activated materials. Annu. Rev. Mater. Res. 2014, 44, 299-330. [CrossRef]

15. Shi, C.; Ana, F.-J.; Palomo, A. New cements for the 21st century: The pursuit of an alternative to Portland cement. Cem. Concr. Res. 2011, 41, 750-763. [CrossRef]

16. Liew, Y.M.; Heah, C.Y.; Mohd Mustafa, A.B.; Kamarudin, H. Structure and properties of clay-based geopolymer cements: A review. Prog. Mater. Sci. 2016, 83, 595-629. [CrossRef]

17. Rashad, A.M. A comprehensive overview about the influence of different additives on the properties of alkali-activated slag-A guide for Civil Engineer. Constr. Build. Mater. 2013, 47, 29-55. [CrossRef]

18. Costa, J.O.; Borges, P.H.R.; dos Santos, F.A.; Bezerra, A.C.S.; Van den bergh, W.; Blom, J. Cementitious binders and reclaimed asphalt aggregates for sustainable pavement base layers: Potential, challenges and research needs. Constr. Build. Mater. 2020, 265, 120325. [CrossRef]

19. Hoy, M.; Horpibulsuk, S.; Rachan, R.; Chinkulkijniwat, A.; Arulrajah, A. Recycled asphalt pavement-Fly ash geopolymers as a sustainable pavement base material: Strength and toxic leaching investigations. Sci. Total Environ. 2016, 573, 19-26. [CrossRef]

20. Horpibulsuk, S.; Hoy, M.; Witchayaphong, P.; Rachan, R.; Arulrajah, A. Recycled asphalt pavement-Fly ash geopolymer as a sustainable stabilized pavement material. IOP Conf. Ser. Mater. Sci. Eng. 2017, 273, 012005. [CrossRef]

21. Hoy, M.; Rachan, R.; Horpibulsuk, S.; Arulrajah, A.; Mirzababaei, M. Effect of wetting-Drying cycles on compressive strength and microstructure of recycled asphalt pavement-Fly ash geopolymer. Constr. Build. Mater. 2017, 144, 624-634. [CrossRef]

22. Saride, S.; Avirneni, D.; Challapalli, S. Micro-mechanical interaction of activated fly ash mortar and reclaimed asphalt pavement materials. Constr. Build. Mater. 2016, 123, 424-435. [CrossRef]

23. Mohammadinia, A.; Arulrajah, A.; Sanjayan, J.G.; Disfani, M.M.; Bo, M.W.; Darmawan, S. Strength Development and Microfabric Structure of Construction and Demolition Aggregates Stabilized with Fly Ash-Based Geopolymers. J. Mater. Civ. Eng. 2016, 28, 04016141. [CrossRef]

24. Jallu, M.; Arulrajah, A.; Saride, S.; Evans, R. Flexural fatigue behavior of fly ash geopolymer stabilized-geogrid reinforced RAP bases. Constr. Build. Mater. 2020, 254, 119263. [CrossRef]

25. Hossiney, N.; Sepuri, H.K.; Mohan, M.K.; Arjun, H.R.; Govindaraju, S.; Chyne, J. Alkali-activated concrete paver blocks made with recycled asphalt pavement (RAP) aggregates. Case Stud. Constr. Mater. 2020, 12, e00322. [CrossRef]

26. Rahman, S.S.; Khattak, M.J. Mechanistic and microstructural characteristics of roller compacted geopolymer concrete using reclaimed asphalt pavement. Int. J. Pavement Eng. 2021, 1-19. [CrossRef]

27. Miranda, T.; Leitão, D.; Oliveira, J.; Corrêa-Silva, M.; Araújo, N.; Coelho, J.; Fernández-Jiménez, A.; Cristelo, N. Application of alkali-activated industrial wastes for the stabilisation of a full-scale (sub)base layer. J. Clean. Prod. 2020, 242, 118427. [CrossRef]

28. Wang, S.-D.; Scrivener, K.L.; Pratt, P.L. Factors affecting the strength of alkali-activated slag. Cem. Concr. Res. 1994, 24, 1033-1043. [CrossRef]

29. Pavel, K.; Oleg, P.; Hryhorii, V.; Serhii, L. The Development of Alkali-activated Cement Mixtures for Fast Rehabilitation and Strengthening of Concrete Structures. Procedia Eng. 2017, 195, 142-146. [CrossRef]

30. Wang, S.-D.; Scrivener, K.L. Hydration products of alkali activated slag cement. Cem. Concr. Res. 1995, 25, 561-571. [CrossRef]

31. NBN EN 12697: 2020. European Committee for Standardization, Bituminous Mixtures_Test Methods-Part 1: Soluble Binder Content; European Committee for Standardization: Brussels, Belgium, 2020.

32. Shi, C. Strength, pore structure and permeability of alkali-activated slag mortars. Cem. Concr. Res. 1996, 26, 1789-1799. [CrossRef]

33. Duran Atiş, C.; Bilim, C.; Çelik, Ö.; Karahan, O. Influence of activator on the strength and drying shrinkage of alkali-activated slag mortar. Constr. Build. Mater. 2009, 23, 548-555. [CrossRef]

34. Palacios, M.; Puertas, F. Effect of superplasticizer and shrinkage-reducing admixtures on alkali-activated slag pastes and mortars. Cem. Concr. Res. 2005, 35, 1358-1367. [CrossRef]

35. NBN EN 196-1: 2016. European Committee for Standardization, Methods of Testing Cement_Part 1: Determination of Strength; European Committee for Standardization: Brussels, Belgium, 2016.

36. Fernandez-Jimenez, A.; Puertas, F.; Arteaga, A. Determination of kinetic equations of alkaline activation of blast furnace slag by means of calorimetric data. J. Therm. Anal. Calorim. 1998, 52, 945-955. [CrossRef]

37. Liu, S.; Li, Q.; Han, W. Effect of various alkalis on hydration properties of alkali-activated slag cements. J. Therm. Anal. Calorim. 2018, 131, 3093-3104. [CrossRef]

38. Huanhai, Z.; Xuequan, W.; Zhongzi, X.; Mingshu, T. Kinetic study on hydration of alkali-activated slag. Cem. Concr. Res. 1993, 23, 1253-1258. [CrossRef]

39. Kashani, A.; Provis, J.L.; Qiao, G.G.; Van Deventer, J.S.J. The interrelationship between surface chemistry and rheology in alkali activated slag paste. Constr. Build. Mater. 2014, 65, 583-591. [CrossRef]

40. Gebregziabiher, B.S.; Thomas, R.J.; Peethamparan, S. Temperature and activator effect on early-age reaction kinetics of alkaliactivated slag binders. Constr. Build. Mater. 2016, 113, 783-793. [CrossRef] 
41. Shi, X.; Grasley, Z.; Hogancamp, J.; Brescia-Norambuena, L.; Mukhopadhyay, A.; Zollinger, D. Microstructural, Mechanical, and Shrinkage Characteristics of Cement Mortar Containing Fine Reclaimed Asphalt Pavement. J. Mater. Civ. Eng. 2020, $32,1-11$. [CrossRef]

42. El Euch Ben Said, S.; El Euch Khay, S.; Loulizi, A. Experimental Investigation of PCC Incorporating RAP. Int. J. Concr. Struct. Mater. 2018, 12, 1-11. [CrossRef]

43. Komnitsas, K.; Zaharaki, D. Geopolymerisation: A review and prospects for the minerals industry. Miner. Eng. 2007, 20, 1261-1277. [CrossRef]

44. Fernández-Jiménez, A.; Palomo, J.G.; Puertas, F. Alkali-activated slag mortars: Mechanical strength behaviour. Cem. Concr. Res. 1999, 29, 1313-1321. [CrossRef]

45. Diamond, S. Mercury porosimetry. An inappropriate method for the measurement of pore size distributions in cement-based materials. Cem. Concr. Res. 2000, 30, 1517-1525. [CrossRef]

46. Borges, P.H.R.; Banthia, N.; Alcamand, H.A.; Vasconcelos, W.L.; Nunes, E.H.M. Performance of blended metakaolin/blastfurnace slag alkali-activated mortars. Cem. Concr. Compos. 2016, 71, 42-52. [CrossRef]

47. Abraham, S.M.; Ransinchung, G.D.R.N. Pore Structure Characteristics of RAP-Inclusive Cement Mortar and Cement Concrete Using Mercury Intrusion Porosimetry Technique. Adv. Civ. Eng. Mater. 2019, 8, 431-453. [CrossRef]

48. Gao, Y.; Wu, K.; Yuan, Q. Limited fractal behavior in cement paste upon mercury intrusion porosimetry test: Analysis and models. Constr. Build. Mater. 2021, 276, 122231. [CrossRef]

49. Shi, Z.; Shi, C.; Wan, S.; Zhang, Z. Effects of alkali dosage and silicate modulus on alkali-silica reaction in alkali-activated slag mortars. Cem. Concr. Res. 2018, 111, 104-115. [CrossRef]

50. Brand, A.S.; Roesler, J.R. Bonding in cementitious materials with asphalt-coated particles: Part I-The interfacial transition zone. Constr. Build. Mater. 2017, 130, 171-181. [CrossRef]

51. El Euch Ben Said, S.; Euch Khay, S.E.; Achour, T.; Loulizi, A. Modelling of the adhesion between reclaimed asphalt pavement aggregates and hydrated cement paste. Constr. Build. Mater. 2017, 152, 839-846. [CrossRef]

52. Sachet, T.; Balbo, J.T.; Bonsembiante, F.T. Rendering the loss of strength in dry concretes with addition of milled asphalt through microscopic analysis. Rev. IBRACON Estruturas e Mater. 2013, 6, 933-954. [CrossRef]

53. Collins, F.; Sanjayan, J.G. Cracking tendency of alkali-activated slag concrete subjected to restrained shrinkage. Cem. Concr. Res. 2000, 30, 791-798. [CrossRef] 